\title{
Polimorfismo no gene GH1-Pstl associado a características corporais de linhagens de tilápia-do-nilo
}

\author{
Danielly Veloso Blanck(1), Eliane Gasparino(1), Ricardo Pereira Ribeiro(1) e Débora Sommer Marques ${ }^{(1)}$ \\ (1)Universidade Estadual de Maringá, Departamento de Zootecnia, Avenida Colombo, № 5.790, Bloco G-56, Sala 8, CEP 87020-900 Maringá, PR. \\ E-mail: dany.peixegen@gmail.com, egasparino@uem.br, ricardo.peixegen@gmail.com, debora.peixegen@gmail.com
}

\begin{abstract}
Resumo - O objetivo deste trabalho foi determinar a associação de polimorfismos no gene do hormônio de crescimento GH1 às características corporais, em linhagens de tilápia-do-nilo (Oreochromis niloticus). Foram coletados fragmentos da nadadeira caudal de exemplares das linhagens, aos cinco meses de idade, para as análises de "polymerase chain reaction-restriction fragment lenght polymorphism" (PCR-RFLP). Foram realizadas as seguintes mensurações: comprimento total, comprimento padrão, altura, largura e comprimento da cabeça. Realizou-se a amplificação de um fragmento com $652 \mathrm{pb}$ do gene $G H 1$, com subsequente restrição com a enzima PstI. Para a análise de associação do marcador molecular com as características quantitativas, utilizou-se o procedimento GLM do SAS. O polimorfismo descrito para o íntron 1, do gene GH1 da tilápiado-nilo, apresentou correlação significativa com o comprimento total, comprimento padrão, altura e largura corporal. Foi verificado que o genótipo $P$ st $\mathrm{I}^{+/}$está associado ao melhor crescimento, independentemente da linhagem. A associação verificada pode ter ocorrido em razão do efeito direto da regulação do próprio gene $G H$.
\end{abstract}

Termos para indexação: Oreochromis niloticus, enzima de restrição, hormônio do crescimento, PCR-RFLP.

\section{Polymorphism in the GH1-Pstl gene associated to corporal characteristics in Nile tilapia strains}

\begin{abstract}
The objective of this study was to determine the association of polymorphisms in the growth hormone gene GH1 with the corporal characteristics in Nile tilapia (Oreochromis niloticus) strains. Fragments of the caudal fin were collected from 5-month old fishes for analysis by polymerase chain reaction - restriction fragment length polymorphism (PCR-RFLP). The following measurements were accomplished: total length, standard length, height, width, and head length. A fragment with $652 \mathrm{bp}$ of the GH1 gene was amplified with subsequent restriction with the enzyme PstI. For the analysis of the association of the molecular marker with the quantitative traits the SAS GLM procedure was used. The polymorphism described for the intron 1 of the GH1 gene of Nile tilapia had significant correlation with total length, standard length, and body height and width. It was found that the genotype $P s t \mathrm{I}^{+-}$is associated with better performance regardless of strain. Such association may be due to direct effect of the $G H$ gene own regulation.
\end{abstract}

Index terms: Oreochromis niloticus, restriction enzyme, growth hormone, PCR-RFLP.

\section{Introdução}

Os ganhos decorrentes das inovações realizadas na produção animal, nutrição e seleção genética têm sido amplamente explorados na aquicultura, com o intuito de melhorar as taxas de crescimento natural de peixes (Fjalestad et al., 2003). Este crescimento adicional pode proporcionar vantagens como a redução do tempo de produção e melhoria da eficiência e conversão alimentar.

Em um programa de melhoramento genético de tilápias-do-nilo (Oreochromis niloticus), as características de crescimento são as de maior relevância econômica. Segundo Sánchez-Ramos et al. (2006), a totalidade de genes que afetam as características de crescimento ainda é desconhecida, porém, já se tem definida uma série de genes candidatos, como os genes do hormônio do crescimento $(G H)$, da prolactina $(P R L)$, da somatolactina $(S L)$, do fator de crescimento semelhante à insulina $(I G F)$ e da miostatina (MSTN).

A estrutura do gene $G H$ de tilápias-do-nilo foi determinada por Ber \& Daniel (1992). Segundo os autores, o gene $G H$ da tilápia-do-nilo possui 3.165 pbe é constituído por seis éxons e cinco íntrons, similarmente a outros teleósteos como o salmão-do-atlântico - 
Salmo salar (Johansen et al., 1989) - e a dourada Sparus aurata (Sánchez-Ramos et al., 2004).

Diferentes formas do gene $G H$ estão presentes em várias espécies de vertebrados. A tilápia-do-nilo apresenta dois genes que codificam o hormônio do crescimento, os quais são altamente similares, com arranjo similar de íntrons e éxons que codificam polipeptídeos idênticos. A presença de dois genes $G H$ (GH1 e GH2) no genoma de tilápia, segundo Ber \& Daniel (1993), pode ser consequência de um evento de duplicação relativamente recente.

De acordo com Gross \& Nilsson (1999), em razão do alto impacto na regulação do crescimento e por estar envolvido em diversas outras funções metabólicas, o gene $G H$ é um alvo potencial para estudos de variação genética e de sua associação com características de crescimento de peixes. Variações no gene $G H$ se mostraram associadas a várias características quantitativas (crescimento, qualidade de carne, produção de ovos, produção de leite, resistência à doenças etc.), em aves, bovinos e suínos (Kuhnlein et al., 1997; Di Stasio et al., 2003; Tambasco et al., 2003; Zhou et al., 2005; Faria et al., 2006; Katoh et al., 2008). Em peixes como o salmão-do-atlântico, o linguado (Paralichthys olivaceus) e a dourada, alguns estudos de associação de polimorfismos no gene $G H$ com o peso já têm sido relatados (Gross \& Nilsson, 1999; Kang et al., 2002; Sánchez-Ramos et al., 2006). No entanto, associações com outras características de interesse, em diferentes ambientes, são ainda escassas.

Estudos de associações podem ser aplicados como critério de seleção em programas de melhoramento genético de espécies aquícolas.

O objetivo deste trabalho foi investigar a associação do polimorfismo PstI, no íntron 1 do gene do hormônio de crescimento $G H 1$, com as características de desempenho das linhagens de tilápia-do-nilo: Chitralada e GIFT ("genetically improved farmed tilapia").

\section{Material e Métodos}

Foram utilizados 321 animais, provenientes de um experimento de avaliação de desempenho de linhagens de tilápia-do-nilo cultivadas em tanques-rede, sob condições idênticas, em que 178 exemplares pertenciam à linhagem Chitralada (não selecionada) e 143 à linhagem GIFT. Os alevinos revertidos da linhagem Chitralada (11 a geração no Brasil) foram obtidos de uma piscicultura localizada em Palotina, PR, e os da linhagem GIFT (1 $1^{\text {a }}$ geração no Brasil), obtidos da Estação Experimental de Piscicultura, da Universidade Estadual de Maringá, Maringá, PR. O experimento de desempenho das linhagens em tanques-rede foi realizado nos meses de abril a agosto de 2007 , no rio do Corvo, que compõe o Lago de Rosana, no Município de Diamante do Norte, PR.

No momento do abate dos animais, aos cinco meses de idade, foram coletados fragmentos da nadadeira caudal dos 321 exemplares de ambas as linhagens para as análises de "polymerase chain reaction-restriction fragment lenght polymorphism" (PCR-RFLP). Foram realizadas as seguintes mensurações: comprimentototal, comprimento padrão, altura, largura e comprimento da cabeça. As amostras foram acondicionadas em microtubos com etanol a 90\% e levadas ao Laboratório de Biologia Molecular, do Departamento de Zootecnia, da Universidade Estadual de Maringá.

As extrações do material genômico foram realizadas conforme protocolo que utiliza $\mathrm{NaCl}$ saturado (Aljanabi \& Martinez, 1997), com modificações. Realizaram-se três lavagens das amostras com etanol a $70 \%$, tendo-se adicionado posteriormente $550 \mu \mathrm{L}$ de tampão de lise $\left(50 \mathrm{mmol} \mathrm{L}^{-1}\right.$ de Tris- $\mathrm{HCl}, 50 \mathrm{mmol} \mathrm{L}^{-1}$ de EDTA, $100 \mathrm{mmol} \mathrm{L}^{-1}$ de $\mathrm{NaCl}$ e $1 \%$ de SDS) e $5 \mu \mathrm{L}$ de proteinase $\mathrm{K}\left(200 \mu \mathrm{g} \mathrm{mL}^{-1}\right)$. As amostras foram incubadas em banho-maria, a $55^{\circ} \mathrm{C}$ durante a noite e, após esse período, adicionaram-se $600 \mu \mathrm{L}$ de $\mathrm{NaCl}\left(5 \mathrm{~mol} \mathrm{~L}^{-1}\right)$ a cada amostra, as quais foram centrifugadas a $12.400 \mathrm{~g}$ por $10 \mathrm{~min}$. De cada amostra, coletaram-se $800 \mu \mathrm{L}$ de sobrenadante, que foram transferidos para outro microtubo com adição de $700 \mu \mathrm{L}$ de etanol absoluto a $4^{\circ} \mathrm{C}$. Depois de completamente precipitado, o DNA foi lavado, seco em estufa a $37^{\circ} \mathrm{C}$ e ressuspendido em $100 \mu \mathrm{L}$ de tampão TE $\left(10 \mathrm{mmol} \mathrm{L}^{-1}\right.$ de Tris pH 8 e $1 \mathrm{mmol} \mathrm{L}^{-1}$ de EDTA). A extração e a integridade das amostras de DNA foram avaliadas em gel de agarose a $0,8 \%$, revelado com $0,5 \mu \mathrm{g} \mathrm{mL}^{-1}$ de brometo de etídeo e visualizado em transluminador com luz ultravioleta. As amostras foram quantificadas e padronizadas a $100 \mathrm{ng} \mu \mathrm{L}^{-1}$ de DNA e estocadas a $-20^{\circ} \mathrm{C}$, até o momento das amplificações.

Um par de iniciadores específicos (5'-CAGCGGT GTTTTTTCATGT-3' e 5'-CGGTTCCCTTGACATC AAAT-3') foram construídos conforme a sequência referência do gene $G H 1$ de tilápia-do-nilo (Ber \& Daniel, 1993), obtida no GenBank (http://www.ncbi.nlm.nih.gov/), 
pelo número de acesso M97766. O DNA genômico foi amplificado em volume de reação de $25 \mu \mathrm{L}$, em que $24,5 \mu \mathrm{L}$ eram de solução "mix" e $0,5 \mu \mathrm{L}$ de DNA molde (50 ng). Assim, o "mix" foi constituído por: tampão Tris-KCl $1 \mathrm{X}$ (Tris-HCl $20 \mathrm{mmol} \mathrm{L}^{-1} \mathrm{pH} \mathrm{8,4} \mathrm{e}$ $\left.\mathrm{KCl} 50 \mathrm{mmol} \mathrm{L}^{-1}\right), 2 \mathrm{mmol} \mathrm{L}^{-1}$ de $\mathrm{MgCl}_{2}, 0,50 \mu \mathrm{mol} \mathrm{L}^{-1}$ de iniciadores $G H 1-\mathrm{P} 1,0,25 \mathrm{mmol} \mathrm{L}^{-1}$ de dNTPs e 0,6 unidade de Taq DNA Polimerase Platinum. As PCR foram realizadas em termociclador Eppendorf Mastercicle Gradient ou Techne TC-412, programados para 35 ciclos, com passo inicial de desnaturação a $95^{\circ} \mathrm{C}$ por 4 min e passo final de extensão a $72^{\circ} \mathrm{C}$ por $4 \mathrm{~min}$. Cada ciclo foi constituído por $30 \mathrm{~s} \mathrm{a} 95^{\circ} \mathrm{C}, 2 \mathrm{~min}$ a $68^{\circ} \mathrm{C}$ e 1 min e $30 \mathrm{~s} \mathrm{a} 72^{\circ} \mathrm{C}$.

A genotipagem dos animais para o fragmento de $652 \mathrm{pb}$ do gene $G H 1$ foi feita pela técnica PCR-RFLP, que consistiu na digestão dos produtos de PCR com o uso da enzima de restrição PstI, no sítio de restrição 5'-CTGCA $\downarrow$ G-3', localizado no íntron 1 (posição $1.915 \mathrm{pb}$ ) da sequência referência, que gerou fragmentos de restrição com 468 e 184 pb (Figura 1). A reação de digestão dos produtos de PCR foi preparada com buffer $1 \mathrm{X}(1,2 \mu \mathrm{L})$, aproximadamente $500 \mathrm{ng}$ de DNA amplificado $(2 \mu \mathrm{L})$ e uma unidade de enzima de restrição, com volume total de $12 \mu \mathrm{L}$. A digestão foi realizada em termocicladores programados em dois ciclos, um a $37^{\circ} \mathrm{C}$ por 4 horas e outro para a inativação da enzima a $65^{\circ} \mathrm{C}$ a $20 \mathrm{~min}$.

Os genótipos foram avaliados em gel de poliacrilamida desnaturante a $10 \%$, revelado pelo método de coloração com nitrato de prata (Bassam et al., 1991), e comparados ao padrão de peso molecular de $1 \mathrm{~kb}$ Plus. Os genótipos foram determinados nas duas linhagens, conforme a ausência ou presença de sítios de restrição no fragmento do gene $G H 1$, em que o homozigoto $\operatorname{Pst}^{\mathrm{T}}{ }^{/+}$corresponde ao genótipo com o mesmo sítio de restrição nos dois cromossomos, $P s t \mathrm{I}^{+/}$ao genótipo heterozigoto com sítio de restrição em somente uma das fitas, e Pst $\mathrm{I}^{-/-}$ ao genótipo homozigoto em que não houve digestão, em razão de mutações nos sítios de restrição dos dois cromossomos.

A análise de associação entre as características avaliadas e o marcador molecular foi realizada pelo procedimento GLM ("general linear models") do SAS (SAS Institute, 2003), de acordo com o modelo: $\mathrm{y}_{\mathrm{ij}}=\mu+1_{\mathrm{i}}+\mathrm{g}_{\mathrm{j}}+(\mathrm{lg})_{\mathrm{ij}}+\varepsilon_{\mathrm{ij}}$, em que: $\mathrm{y}_{\mathrm{ij}}$ é o valor observado da característica na linhagem i do genótipo $\mathrm{j}$; $\mu$ é o

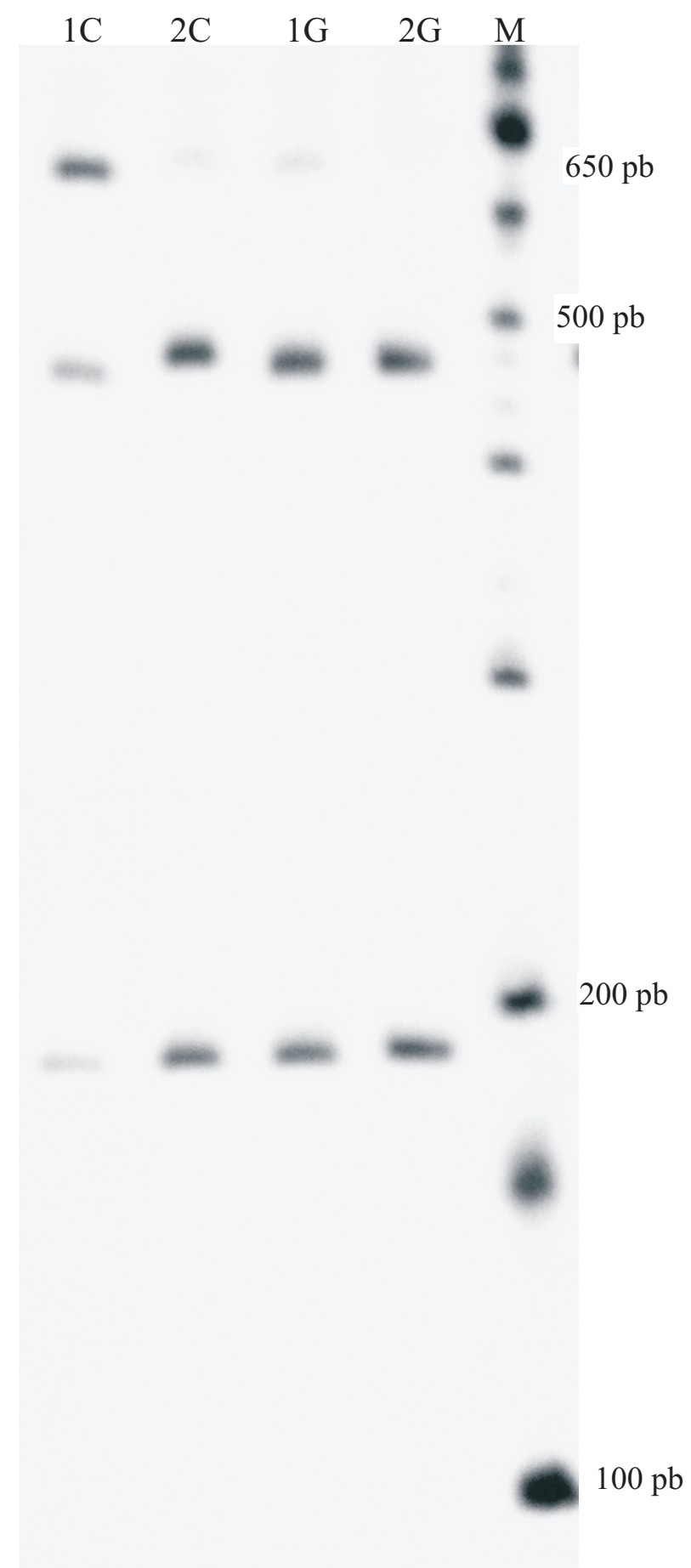

Figura 1. Análise em gel desnaturante de poliacrilamida a $10 \%$, relativo às restrições com a enzima Pst $\mathrm{I}$ do íntron 1 do gene $G H 1$ de tilápia-do-nilo, revelado em nitrato de prata. Canaletas $1 \mathrm{C}$ e $2 \mathrm{C}$ indicam os genótipos heterozigoto $P_{s t \mathrm{I}^{+/-}}(652 \mathrm{pb}, 468 \mathrm{pb}$ e $184 \mathrm{pb})$ e homozigoto Pst $^{+/+}$(468 pb e $184 \mathrm{pb}$ ), respectivamente, da linhagem Chitralada. Canaletas $1 \mathrm{G}$ e $2 \mathrm{G}$ indicam genótipos homozigotos Pst $^{+/+}$(468 pb e 184 pb) da linhagem GIFT. $\mathrm{M}$ indica o padrão de peso molecular de $1 \mathrm{~kb}$ Plus. 
efeito médio global da população; $1_{i}$ é o efeito fixo da linhagem i; $g_{j}$ é o efeito fixo do genótipo j; $(\lg )_{i j}$ é o efeito da interação entre as linhagens e os genótipos; e $\varepsilon_{\mathrm{ij}}$ é o erro aleatório associado a cada observação (Littell et al., 1991). O teste de Tukey $(\mathrm{p}<0,05)$ foi utilizado para a comparação das médias das variáveis mensuradas.

$\mathrm{O}$ genótipo $P_{s t} \mathrm{I}^{-/}$foi excluído das análises por apresentar apenas três indivíduos representantes dessa classe de efeito fixo.

\section{Resultados e Discussão}

De acordo com a sequência referência do gene GH1 da tilápia-do-nilo (Ber \& Daniel, 1993), o par de iniciadores desenhado amplificou satisfatoriamente o fragmento de tamanho esperado de $652 \mathrm{pb}$, tanto na linhagem Chitralada como na GIFT.

A região polimórfica do fragmento de $652 \mathrm{pb}$, do gene GHI das linhagens de tilápia-do-nilo, foi detectada pela enzima PstI, que possui seu sítio de restrição na região não codificadora íntron 1. Variantes polimórficas nos íntrons 1 e 3 do gene $G H$ de dourada foram obtidas com o uso da enzima PstI pela técnica RFLP (Almuly et al., 2000), porém, estudos de associação de polimorfismos obtidos com essa enzima aos caracteres de produção, até o momento, não foram realizados em espécies de peixes.

$\mathrm{O}$ fato de o polimorfismo encontrado neste trabalho ocorrer em região não codificadora não significa que essa mutação seja necessariamente neutra, uma vez que, segundo Gross \& Nilsson (1999), é possível a ocorrência de efeito de ligação (efeito "carona") entre genes e regiões gênicas. A ocorrência de polimorfismos no íntron 1 e sua associação ao crescimento já foram relatadas em peixes como o linguado (Kang et al., 2002), o salmão-do-atlântico (Gross \& Nilsson, 1999), a truta "Artic charr" (Salvelinus alpinus) (Tao \& Boulding, 2003) e a dourada (Sánchez-Ramos et al., 2006). Também foram observados polimorfismos no gene $G H$, em regiões não codificadoras, associados à produção, em bovinos, aves e suínos (Kuhnlein et al., 1997; Zhou et al., 2005; Faria et al., 2006).

Entre as variáveis analisadas nas linhagens Chitralada e GIFT, a altura não diferiu significativamente; nas características restantes, com exceção da largura, a linhagem Chitralada foi superior $(\mathrm{p}<0,05)$. Assim, de maneira geral, a linhagem GIFT, quando cultivada em tanques-rede, apresentou menor desenvolvimento corporal, em relação à linhagem Chitralada (Tabela 1).

Contrariamente aos valores de crescimento das linhagens avaliadas no presente trabalho, Fülber (2007) verificou desempenho superior da linhagem GIFT em relação à Chitralada, cultivadas em sistema semi-intensivo (com baixa taxa de renovação de água e alimentadas com $25 \%$ de PB). Dan \& Little (2000) e Ridha (2006) também observaram desempenho superior da linhagem GIFT em relação à Chitralada, cultivadas tanto em viveiros de terra quanto em gaiolas.

Os resultados do presente trabalho indicam a existência de algum tipo de interação genótipo $\mathrm{x}$ ambiente ou, ainda, que a linhagem GIFT não está bem adaptada às condições brasileiras. Estudos de interação genótipo $\mathrm{x}$ ambiente, com estoques de tilápia-do-nilo, relatam a existência significativa desse tipo de interação (Macaranas et al., 1997; Eknath et al., 2007), em que os viveiros de terra são, provavelmente, os melhores ambientes de cultivo (Eknath et al., 2007). Além de considerações acerca da interação genótipo x ambiente, segundo Osure \& Phelps (2006), estudos de comparações entre linhagens de tilápia devem levar em consideração a forte influência da pressão de seleção, praticada de modo associado ao processo de domesticação, como critérios de escolha da linhagem a ser cultivada.

A variação no gene $G H 1$, observada na tilápia-do-nilo, podeestarassociadadiretamente às características corporais, uma vez que o genótipo heterozigoto $P s t \mathrm{I}^{+/}$foi superior ao genótipo homozigoto $P s t \mathrm{I}^{+/+}$, independentemente da

Tabela 1. Características de desempenho das linhagens de tilápia-do-nilo e dos genótipos GH1-PstI.

\begin{tabular}{|c|c|c|c|c|}
\hline \multirow[t]{2}{*}{ Variável } & \multicolumn{2}{|c|}{ Linhagem } & \multicolumn{2}{|c|}{ Genótipo } \\
\hline & Chitralada & GIFT & $P s t \mathrm{I}^{+/+}$ & $P s t \mathrm{I}^{+/-}$ \\
\hline Comprimento total $(\mathrm{cm})$ & $29,09 \pm 1,52 \mathrm{a}$ & $28,11 \pm 1,47 b$ & $28,51 \pm 1,49 b$ & $29,32 \pm 1,53 a$ \\
\hline Comprimento padrão (cm) & $23,91 \pm 1,22 \mathrm{a}$ & $23,31 \pm 1,19 b$ & $23,54 \pm 1,21 b$ & $24,14 \pm 1,24 \mathrm{a}$ \\
\hline Altura $(\mathrm{cm})$ & $10,09 \pm 0,84 \mathrm{a}$ & $9,97 \pm 0,83 \mathrm{a}$ & $9,99 \pm 0,83 b$ & $10,27 \pm 0,85 \mathrm{a}$ \\
\hline Largura $(\mathrm{cm})$ & $4,50 \pm 0,24 b$ & $4,58 \pm 0,24 \mathrm{a}$ & $4,52 \pm 0,24 b$ & $4,61 \pm 0,24 \mathrm{a}$ \\
\hline Comprimento da cabeça $(\mathrm{cm})$ & $7,37 \pm 0,39 \mathrm{a}$ & $7,09 \pm 0,39 \mathrm{~b}$ & $7,21 \pm 0,38 \mathrm{a}$ & $7,42 \pm 0,39 a$ \\
\hline
\end{tabular}

${ }^{(1)}$ Médias \pm desvio-padrão seguidas de letras iguais, nas linhas, não diferem entre si pelo teste de Tukey, a 5\% de probabilidade. 
linhagem, quanto ao comprimento total, comprimento padrão, altura e largura (Tabela 1). Resultados encontrados em estudos de associação de polimorfismos no gene $G H$, em que os genótipos heterozigotos foram superiores aos homozigotos quanto às características de produção, em outros animais de cultivo (Reis et al., 2001; Kansaku et al., 2003), são corroborados pelos obtidos no presente trabalho. Nenhuma interação entre linhagem e genótipo foi encontrada em relação às características avaliadas.

De acordo com os resultados do presente trabalho, parece coerente a construção de linhagens de tilápia-do-nilo altamente isogênicas para o loco GH1-PstI, para fins de exploração de vigor híbrido e, consequentemente, de desenvolvimento de uma linhagem comercial $\left(F_{1}\right)$ com alto potencial de desempenho.

\section{Conclusões}

1. Existe associação do polimorfismo do gene GH1-PstI com as características de desempenho de linhagens de tilápia-do-nilo.

2. A associação verificada pode ocorrer em razão do efeito direto da regulação do próprio gene do hormônio do crescimento.

\section{Referências}

ALJANABI, S.M.; MARTINEZ, I. Universal and rapid salt-extraction of high quality genomic DNA for PCR-based techniques. Nucleic Acids Research, v.25, p.4692-4693, 1997.

ALMULY, R.; CAVARI, B.; FERSTMAN, H.; KOLODNY, O.; FUNKENSTEIN, B. Genomic structure and sequence of the gilthead seabream (Sparus aurata) growth hormone encoding gene: identification of minisatellite polymorphism in intron I. Genome, v.43, p.836-845, 2000.

BASSAM, B.J.; CAETANO-ANOLLÉS, G.; GRESSHOFF, P.M. Fast and sensitive silver staining of DNA in polyacrylamide gels. Analytical Biochemistry, v.196, p.80-83, 1991.

BER, D.; DANIEL, V. Sequence analysis suggests a recent duplication of the growth hormone-encoding gene in Tilapia nilotica. Gene, v.125, p.143-150, 1993.

BER, D.; DANIEL, V. Structure and sequence of the growth hormone-encoding gene from Tilapia nilotica. Gene, v.113, p.245-250, 1992.

DAN, N.C.; LITTLE, D.C. The culture performance of monosex and mixed-sex new-season and overwintered fry in three strains of Nile tilapia (Oreochromis niloticus) in Northern Vietnam. Aquaculture, v.184, p.221-231, 2000.
DI STASIO, L.; BRUGIAPAGLIA, A.; DESTEFANIS, G.; ALBERA, A.; SARTORE, S. GHI as candidate gene for variability of meat production traits in Piemontese cattle. Journal of Animal Breeding and Genetics, v.120, p.358-361, 2003.

EKNATH, A.E.; BENTSEN, H.B.; PONZONI, R.W.; RYE, M.; NGUYEN, N.H.; THODESEN, J.; GJERDE, B. Genetic improvement of farmed tilapias: composition and genetic parameters of a synthetic base population of Oreochromis niloticus for selective breeding. Aquaculture, v.273, p.1-14, 2007.

FARIA, D.A. de; GUIMARÃES, S.E.F.; LOPES, P.S.; PIRES, A.V.; PAIVA, S.R.; SOLLERO, B.P.; WENCESLAU, A.A. Association between G316A growth hormone polymorphism and economic traits in pigs. Genetics and Molecular Biology, v.29, p.634-640, 2006.

FJALESTAD, K.T.; MOEN, T.; GOMEZ-RAYA, L. Prospects for genetic technology in salmon breeding programmes. Aquaculture Research, v.34, p.397-406, 2003.

FÜLBER, V.M. Desempenho de três linhagens de tilápia-do-nilo (Oreochromis niloticus) em diferentes fases, densidades e níveis de proteína. 2007. 29p. Dissertação (Mestrado) - Universidade Estadual de Maringá, Maringá.

GROSS, R.; NILSSON, J. Restriction fragment length polymorphism at the growth hormone 1 gene in Atlantic salmon (Salmo salar L.) and its association with weight among the offspring of a hatchery stock. Aquaculture, v.173, p.73-80, 1999.

JOHANSEN, B.; JOHNSEN, O.C.; VALLA, S. The complete nucleotide sequence of the growth hormone gene from Atlantic salmon (Salmo salar). Gene, v.77, p.317-324, 1989.

KANG, J.H.; LEE, S.J.; PARK, R.S.; RYU, H.Y. DNA polymorphism in the growth hormone gene and its association with weight in olive flounder Paralichthys olivaceus. Fisheries Science, v.68, p.494-498, 2002.

KANSAKU, N.; NAKADA, A.; OKABAYASHI, H.; GUÉMENÉ, D.; KUHNLEIN, U.; ZADWORNY, D.; SHIMADA, K. DNA polymorphism in the chicken growth hormone gene: association with egg production. Animal Science Journal, v.74, p.243-244, 2003.

KATOH, K.; KOUNO, S.; OKAZAKI, A.; SUZUKI, K.; OBARA, $\mathrm{Y}$. Interaction of $\mathrm{GH}$ polymorphism with body weight and endocrine functions in Japanese black calves. Domestic Animal Endocrinology, v.34, p.25-30, 2008.

KUHNLEIN, U.; NI, L.; WEIGEND, S.; GAVORA, J.S.; FAIRFULL, W.; ZADWORNY, D. DNA polymorphisms in the chicken growth hormone gene: response to selection for disease resistance and association with egg production. Animal Genetics, v.28, p.116-123, 1997.

LITTELL, R.C.; FREUND, R.J.; SPECTOR, P.C. SAS system for linear models. $3^{\text {rd }}$.ed. Cary: SAS Institute, 1991.

MACARANAS, J.M.; MATHER, P.B.; LAL, S.N.; VEREIVALU, T.; LAGIBALAVU, M.; CAPRA, M.F. Genotype and environment: a comparative evaluation of four tilapia stocks in Fiji. Aquaculture, v.150, p.11-24, 1997.

OSURE, G.O.; PHELPS, R.P. Evaluation of reproductive performance and early growth of four strains of Nile tilapia 
(Oreochromis niloticus, L.) with different histories of domestication. Aquaculture, v.253, p.485-494, 2006.

REIS, C.; NAVAS, D.; PEREIRA, M.; CRAVADOR, A. Growth hormone AluI polymorphism analysis in eight portuguese bovine breeds. Archivos de Zootecnia, v.50, p.41-48, 2001.

RIDHA, M.T. Comparative study of growth performance of three strains of Nile tilapia, Oreochromis niloticus L. at two stocking densities. Aquaculture Research, v.37, p.172-179, 2006.

SÁNCHEZ-RAMOS, I.; BARRIOS, M.; CROSS, I.; REBORDINOS, L. Identificación de RFLP en genes relacionados con el crecimiento en dorada Sparus aurata L., 1758. Boletín Instituto Espanõl de Oceanografía, v.21, p.253-259, 2006.

SÁNCHEZ-RAMOS, I.; CROSS, I.; REBORDINOS, L. Determination of RFLP's in genes related to growth in gilthead sea bream (Sparus aurata). In: ADAMS, S.; OLAFSEN, J.A. (Ed.). Biotechnologies for quality: extended abstracts and short communications. Barcelona: European Aquaculture Society, 2004. p.713-714.

SAS INSTITUTE. User's guide. Versão 9.1.3. Cary: SAS Institute, 2003.

TAMBASCO, D.D.; PAZ, C.C.P.; TAMBASCO-STUDART, M.; PEREIRA, A.P.; ALENCAR, M.M.; FREITAS, A.R.; COUTINHO, L.L.; PACKER, I.U.; REGITANO, L.C.A. Candidate genes for growth traits in beef cattle crosses Bos taurus $\mathrm{x}$ Bos indicus. Journal of Animal Breeding and Genetics, v.120, p.51-56, 2003.

TAO, W.J.; BOULDING, E.G. Associations between single nucleotide polymorphisms in candidate genes and growth rate in Artic charr (Salvelinus alpinus L.). Heredity, v.91, p.60-69, 2003.

ZHOU, G.L.; JIN, H.G.; LIU, C.; GUO, S.L.; ZHU, Q.; WU, Y.H. Association of genetic polymorphism in $G H$ gene with milk production traits in Beijing Holstein cows. Journal of Biosciences, v.30, p.595-598, 2005.

Recebido em 8 de setembro de 2008 e aprovado em 5 de junho de 2009 